\title{
Transesterification of vegetable oil by ethanol in the presence of heterogeneous catalysts
}

\author{
Yurii Melnyk $^{1}$, Stepan Melnyk ${ }^{2}$, Halyna Mahorivska ${ }^{3}$ \\ 1. Department of Organic Products Technology, Lviv Polytechnic National University, UKRAINE, Lviv, S. \\ Bandera str., 12, E-mail: yurii.r.melnyk@lpnu.ua
}

2. Department of Organic Products Technology, Lviv Polytechnic National University, UKRAINE, Lviv, S. Bandera str., 12, E-mail: stepan.r.melnyk@lpnu.ua

3. Department of Chemical Technology of Silicate Materials, Lviv Polytechnic National University, UKRAINE, Lviv, S. Bandera str., 12, E-mail: halyna.y.mahorivska@lpnu.ua

\begin{abstract}
Transesterification of vegetable oil by ethanol in the presence of heterogeneous catalysts has been investigated. Zinc and nickel(II) oxides and cation exchange resin CU-2-8 with immobilized $\mathrm{Sn}^{2+}$ and $\mathrm{Zn}^{2+}$ ions were shown to have the highest catalytic activity among an investigated catalysts. The optimal concentration of catalysts and optimal molar ratio triglycerides : alcohol have been established.
\end{abstract}

Keywords - transesterification, triglycerides, oxides of metals, cation exchange resin CU-2-8, ethanol.

\section{Introduction}

Acid and basic homogeneous and heterogeneous catalysts are used for the transesterification process of vegetable oils triglycerides (TG) by aliphatic alcohols [1, 2]. Heterogeneous catalysts can be easily separated from the reaction mixture and further used many times in the process. When using heterogeneous catalysts, it is easier to realize a continuous process [2-4]. The amount of heterogeneous catalysts using in transesterification process is quite limited. The aim of research is to investigate a metal oxides and cation exchange resin CU-2-8 with immobilized cations as a transesterification reaction catalyst of vegetable oils triglycerides by ethyl alcohol.

\section{Results and discussion}

Sunflower, rapeseed and linseed oils were used as the TG raw sources. Anhydrous ethanol was used as an ethyl alcohol raw source. Fine powders of the metal oxides $\mathrm{ZnO}, \mathrm{NiO}, \mathrm{MgO}$, $\mathrm{SnO}_{2}, \mathrm{MnO}, \mathrm{PbO}, \mathrm{Al}_{2} \mathrm{O}_{3}, \mathrm{Cr}_{2} \mathrm{O}_{3}$ (all were analytical grade) were used as the catalysts. The cation exchange resin CU-2-8 in $\mathrm{H}^{+}$-form and the cation exchange resin CU-2-8 with an immobilized ions of $\mathrm{Co}^{2+}, \mathrm{Zn}^{2+}, \mathrm{Ni}^{2+}, \mathrm{Sn}^{2+}, \mathrm{Cu}^{2+}$ were used as the catalysts. Transesterification of TG was carried out with anhydrous ethanol at $75{ }^{\circ} \mathrm{C}$ and ethanol : TG molar ratio of $(3.6-8,0): 1$. The amounts of TG were recalculated to glycerol trioleate. The content of the metal oxides was from $0.13 \mathrm{wt} \%$ to $0.50 \mathrm{wt} \%$ and the content of cation exchange resin was from $0,5 \mathrm{wt} \%$ to $4,0 \mathrm{wt} \%$. The effect of the catalyst content was studied using zinc oxide. Its content was varied in the range from $0.13 \mathrm{wt} \%$ to $0.50 \mathrm{wt} \%$ in the reaction mixture. The transesterification reaction was carried out during 150-180 minutes.

The transesterification of TG by ethanol in the presence of heterogeneous catalysts was carried out in a glass three-necked flask equipped with a reflux condenser under intensive stirring. The samples were taken after each 30 minutes. The ethanol content was determined by chromatography, the acid number - by titrimetry after end of the reaction.

Chromatographic analysis of the reaction mixture was performed using a gas-liquid chromatograph LHM-80 with a thermal conductivity detector under the conditions given in [5]. The acid number was determined by alkalimetric titration [6]. 
It was shown high catalytic activity of fine metal oxides as transesterification catalysts of TG by anhydrous ethanol. Zinc and nickel (II) oxides were found to be the most active catalysts among the studied metal oxides. It was established that the increase in ethanol : TG molar ratio to 4,1: 1 and more results an almost complete conversion of sunflower oil TG. It was also found that in the presence of zinc and nickel (II) oxides an esterification reaction of FFA present in the vegetable raw material takes place.

It was established that the activity of transesterification reaction catalysts based on the cation exchange resin with immobilized metal ions depends on the cation type. It was shown that the cation exchange resin with immobilized ions of $\mathrm{Sn}^{2+}$ and the cation exchange resin in $\mathrm{H}^{+}$form have the highest activity in the transesterification reaction of TG by ethyl alcohol. In the presence of the examined catalysts conversion of TG decreases with an increase in the alcohol chain length. It was established that optimal molar ratio of ethanol : TG is (4-5):1.

Extreme dependence of the initial rate of the transesterification reaction and triglycerides conversion on the content of the heterogeneous catalysts was established. It was established that optimal content of cation exchange resin with immobilized metal ions is $2 \mathrm{wt} \%$ and optimal content of metal oxides is $0.25-0.30 \mathrm{wt} \%$.

\section{Conclusion}

Thus it can be assume that the examined catalysts demonstrate high activity in the transesterification reaction of TG by ethyl alcohol. The catalysts make it possible to achieve high transaction rate of raw materials. The obtained results indicate the applying feasibility of catalysts based on the cation exchange resin with immobilized metal ions or metal oxides in the transesterification reaction of TG by ethanol.

\section{References}

[1] Van Gerpen, J. (2005). Biodiesel processing and production. Fuel Process. Technol., 86 1097-1107. https://doi.org/10.1016/j.fuproc.2004.11.005.

[2] Leung, D. Y., Wu, X., Leung, H. M. (2010). A review on biodiesel production using catalyzed transesterification. Appl. Energ., 87, 1083-1095. https://doi.org/10.1016/j.apenergy.2009.10.006.

[3] Shibasaki-Kitakawa, N., Honda, H., Kuri-bayashi, H., Toda, T., Fukumura, T. \& Yonemoto, T. (2007). Biodiesel production using anionic ion-exchange resin as heterogeneous catalyst. Bioresource Technology, 98(2), 416-421. https://doi.org/10.1016/j.biortech.2005.12.010.

[4] Yan, S., DiMaggio, C., Mohan, S., Kim, M., \& Salley, S. O. (2010). Advancements in heterogeneous catalysis for biodiesel synthesis. Topics Catal., 53(11-12), 721-736. https://doi.org/10.1007/s11244-010-9460-5.

[5] Melnyk, Yu., Starchevskyi, R., \& Melnyk, S. (2019) Transesterification of triglycerides by ethanol in the presence of metal oxides. Bulletin of NTU "KhPI". Series: New solutions in modern technologies, 5(1330), 132-138. https://doi.org/10.20998/2413-4295.2019.05.17.

[6] Biocyclopedia.com. Methodology for Lipids. Retrieved February 13, 2021, from http://www.biocyclopedia.com/index/plant_protocols/lipids/Estimation_of_free_fatty_acid s.php 